\title{
Skin Cancer Management During the COVID-19 Pandemic
}

\author{
Jacob Thomas, BS; Anthony M. Rossi, MD
}

\section{PRACTICE POINTS}

- Consider the rate of cases and transmission in your area during a pandemic surge when triaging surgical and nonsurgical cases.

- If performing head and neck surgical procedures or cosmetic procedures in which the patient cannot wear a mask, consider testing them 24 to 48 hours before the procedure.

- Follow Centers for Disease Control and Prevention (CDC) guidelines concerning screening asymptomatic patients. Also, follow CDC guidelines on testing patients who have had prior infections.

- Ensure proper personal protective equipment for yourself and staff, including the use of properly fitting N95 respirators and face shields.

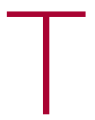
he coronavirus disease 2019 (COVID-19) pandemic, caused by severe acute respiratory syndrome novel coronavirus 2 (SARS-CoV-2), has presented a unique challenge to providing essential care to patients. Increased demand for health care workers and medical supplies, in addition to the risk for COVID-19 infection and asymptomatic transmission of SARS-CoV-2 among health care workers and patients, prompted the delay of nonessential services during the surge of cases this summer. ${ }^{1}$ Key considerations for continuing operation included current and projected COVID-19 cases in the region, ability to implement telehealth, staffing availability, personal protective equipment availability, and office capacity. ${ }^{2}$ Providing care that is deemed essential often was determined by the urgency of the treatment or service.

The Centers for Medicare \& Medicaid Services outlined a strategy to stratify patients, based on level of acuity, during the COVID-19 surge $^{3}$ :

- Low-acuity treatments or services: includes routine primary, specialty, or preventive care visits. They should be postponed; telehealth follow-ups should be considered.

- Intermediate-acuity treatments or services: includes pediatric and neonatal care, follow-up visits for existing conditions, and evaluation of new symptoms (including those consistent with COVID-19). These services should initially be evaluated using telehealth, then triaged to the appropriate site and level of care.

- High-acuity treatments or services: address symptoms consistent with COVID-19 or other severe disease, of which the lack of in-person evaluation would result in harm to the patient.

Employees in hospitals and health care clinics were classified as essential, but dermatologists were not given

\footnotetext{
Mr. Thomas is from Weill Cornell Medical College, New York, New York. Dr. Rossi is from the Dermatology Service, Department of Medicine, Memorial Sloan Kettering Cancer Center, New York.

Mr. Thomas reports no conflict of interest. Dr. Rossi has received grant funding from the American Society for Dermatologic Surgery/American Society for Dermatologic Surgery Association, LEO Innovation Lab, Regen Pharmaceuticals, The Skin Cancer Foundation, and the Society of Memorial Sloan Kettering Cancer Center, and has received the A. Ward Ford Memorial Research Grant. He also has served as an advisory board member, consultant, or educational presenter for Allergan, Inc; Biofrontera; Canfield Scientific, Inc; Cutera, Inc; DynaMed; Evolus; Elekta; Galderma Laboratories, LP; LAM Therapeutics; Merz Pharmaceuticals GmbH; PerfAction Technologies; Quantia, Inc; and Skinuvia.

This research was funded in part by a grant from the National Cancer Institute/National Institutes of Health (P30-CA008748) made to Memorial Sloan Kettering Cancer Center.
}

Correspondence: Anthony M. Rossi, MD, 530 E 74th St, Office 9104, New York, NY 10021 (rossia@mskcc.org).

doi:10.12788/cutis.0146 
explicit direction regarding clinic operation. Many practices have restricted services, especially those in an area of higher COVID-19 prevalence. However, the challenge of determining day-to-day operation may have been left to the provider in most cases. ${ }^{4}$ As many states in the United States continue to relax restrictions, total cases and the rate of positivity of COVID-19 have been sharply rising again, after months of decline, ${ }^{5}$ which suggests increased

\section{TABLE 1. National Comprehensive Cancer Network Guidelines for Melanoma}

\begin{tabular}{|c|c|}
\hline Staging & Recommendation \\
\hline Diagnostic biopsies & $\begin{array}{l}\text { Invasive lesions: excisional/complete saucerization biopsy should be attempted to remove the lesion; } \\
\text { melanoma in situ: broad shave biopsies; telehealth evaluations for new patients should be considered while } \\
\text { complete and physical history may be delayed until the day of surgery }\end{array}$ \\
\hline Melanoma in situ & Delay WLE for up to 3 mo \\
\hline $\begin{array}{l}\text { T1 melanoma } \\
\text { ( } \leq 1 \mathrm{~mm} \text { thickness) }\end{array}$ & $\begin{array}{l}\text { Delay WLE for up to } 3 \text { mo as long as the biopsy removed the majority of the lesion; if a large clinical lesion } \\
\text { exists, perform complete excisional biopsy with } 1-\mathrm{cm} \text { surgical margins in the office/outpatient setting; delay } \\
\text { WLE for invasive melanomas of any depth for which prior biopsy showed clear histologic margins or MIS }\end{array}$ \\
\hline $\begin{array}{l}\text { T3/T4 melanomas } \\
\text { (>2 } \mathrm{mm} \text { thickness) }\end{array}$ & $\begin{array}{l}\text { Should take priority over T1/T2 melanomas ( } \leq 2 \mathrm{~mm} \text { thickness); complete removal of any melanoma that is } \\
\text { partially/incompletely biopsied in which a large clinical residual lesion is evident }\end{array}$ \\
\hline SLNB & Delay for up to 3 mo unless it may be performed simultaneously with WLE in the operating room \\
\hline Follow-up & Defer for 3-6 mo in asymptomatic patients \\
\hline
\end{tabular}

Abbreviations: WLE, wide local excision; MIS, melanoma in situ; SLNB, sentinel lymph node biopsy.

TABLE 2. European Society for Medical Oncology Guidelines for Melanoma ${ }^{9}$

\begin{tabular}{|c|c|c|}
\hline Priority & Recommendation & Additional considerations \\
\hline $\begin{array}{l}\text { Outpatient } \\
\text { High }\end{array}$ & $\begin{array}{l}\text { New diagnosis of invasive primary melanoma and postoperative } \\
\text { patients with complications unless tumor is Tis or T1a and wide } \\
\text { excision performed }\end{array}$ & $\begin{array}{l}\text { Patients on PD-1 blockade, } \\
\text { double dose with double } \\
\text { interval to reduce visits; } \\
\text { telemedicine visits for } \\
\text { patients on TKIs }\end{array}$ \\
\hline \multicolumn{3}{|l|}{ High/medium } \\
\hline Medium & $\begin{array}{l}\text { Telemedicine visits between } 2 \text { treatments for patients on } \\
\text { immunotherapy; postoperative patients without complications }\end{array}$ & \\
\hline Low & $\begin{array}{l}\text { Telemedicine visits for follow-up patients with no active treatment and } \\
\text { melanoma survivors as well as for psychological support; patients with } \\
\text { dysplastic nevi syndrome or other increased risk conditions }\end{array}$ & \\
\hline \multicolumn{3}{|l|}{ Surgery } \\
\hline High & $\begin{array}{l}\text { Curative resection for stage III melanoma, surgical management of } \\
\text { complications, patients in neoadjuvant trials }\end{array}$ & \\
\hline High/medium & $\begin{array}{l}\text { WLE and SLNB for new diagnosis of invasive primary melanoma T1b or } \\
\text { higher; delaying surgery of T1 and T2 is acceptable; T1a or lower: WLE } \\
\text { with medium priority }\end{array}$ & \\
\hline
\end{tabular}

Abbreviations: TKI, tyrosinase kinase inhibitor, WLE, wide local excision; SLNB, sentinel lymph node biopsy. 
transmission of SARS-CoV-2 and potential resurgence of the high case burden on our health care system. Furthermore, a lack of a widely distributed vaccine or herd immunity suggests we will need to take many of the same precautions as in the first surge. ${ }^{6}$

In general, patients with cancer have been found to be at greater risk for adverse outcomes and mortality after COVID-19. ${ }^{7}$ Therefore, resource rationing is particularly concerning for patients with skin cancer, including melanoma, Merkel cell carcinoma, mycosis fungoides, and keratinocyte carcinoma. Triaging patients based on level of acuity, type of skin cancer, disease burden, host immunosuppression, and risk for progression must be carefully considered in this population. ${ }^{2}$ Treatment and follow-up present additional challenges.

Guidelines provided by the National Comprehensive Cancer Network (NCCN) and the European Society for Medical Oncology (ESMO) elaborated on key considerations for the treatment of melanoma, keratinocyte carcinoma, and Merkel cell carcinoma during the COVID-19 pandemic. ${ }^{8-10}$ Guidelines from the NCCN concentrated on clear divisions between disease stages to determine provider response. Guidelines for melanoma patients proposed by the ESMO assign tiers by valuebased priority in various treatment settings, which offered flexibility to providers as the COVID-19 landscape continued to change. Recommendations from the NCCN and ESMO are summarized in Tables 1 to 5 .
Although these guidelines initially may have been proposed to delay treatment of lower-acuity tumors, such delay might not be feasible given the unknown duration of this pandemic and future disease waves. One review of several studies, which addressed the outcomes on melanoma survival following the surgical delay recommended by the NCCN, revealed contradictory evidence. ${ }^{12}$ Further, sufficiently powered studies will be needed to better understand the impact of delaying treatment during the summer COVID-19 surge on patients with skin cancer. Therefore, physicians must triage patients accordingly to manage and treat while also preventing disease spread.

\section{Tips for Performing Dermatologic Surgery}

Careful consideration should be made to protect both the patient and staff during office-based excisional surgery during the COVID-19 pandemic. To minimize the risk of transmission of SARS-CoV-2, patients and staff should (1) be screened for symptoms of COVID-19 at least 48 hours prior to entering the office via telephone screening questions, and (2) follow proper hygiene and contact procedures once entering the office. Consider obtaining a nasal polymerase chain reaction swab or saliva test 48 hours prior to the procedure if the patient is undergoing a head and neck procedure or there is risk for transmission.

Guidelines from the ESMO recommended that all patients undergoing surgery or therapy should be swabbed for SARS-CoV-2 before each treatment. ${ }^{11}$

\section{TABLE 3. National Comprehensive Cancer Network Guidelines for Advanced Melanoma ${ }^{9}$}

\begin{tabular}{|c|c|}
\hline Stage & Recommendation \\
\hline $\begin{array}{l}\text { Stage III melanoma } \\
\text { (regional nodal) }\end{array}$ & $\begin{array}{l}\text { Defer complete lymph node dissection and perform nodal ultrasound surveillance or other } \\
\text { imaging surveillance following positive SLNB (if the patient is asymptomatic, surveillance imaging } \\
\text { may be delayed for 3-6 mo); delay therapeutic lymphadenectomy in patients with clinically palpable } \\
\text { regional nodes; offer neoadjuvant systemic therapy immune checkpoint blockage or BRAF/MEK } \\
\text { inhibitors; exceptions to prioritizing neoadjuvant therapy include those patients in whom neoadjuvant } \\
\text { therapy is not possible or who previously have failed systemic therapy, if delayed resection may } \\
\text { increase morbidity, or when metastatic node(s) are invading vital structures }\end{array}$ \\
\hline $\begin{array}{l}\text { Stage III adjuvant } \\
\text { therapy }\end{array}$ & $\begin{array}{l}\text { Therapy may be initiated up to } 12 \text { wk from time of definitive surgical resection of melanoma (adjuvant } \\
\text { therapy has not been shown to improve survival in melanoma patients, defer in patients with less } \\
\text { than } 50 \% \text { chance of relapse); consider the risks and benefits of drugs and therapies that may expose } \\
\text { the patient to increased risk profile and side effects, in addition to an increased number of visits } \\
\text { (ie, immune therapy options over immunosuppressive regimens) }\end{array}$ \\
\hline Stage IV melanoma & $\begin{array}{l}\text { While decisions about ICB should be individualized, agents with the lowest toxicity profile are } \\
\text { preferred at this time; single-agent anti-PD-1 is recommended over the combination of ipilimumab } \\
\text { and nivolumab for every patient without brain metastasis due to more substantial inflammatory side } \\
\text { effects, possible exacerbation of COVID-19, and possible need for steroids/immunosuppressants } \\
\text { that may adversely affect COVID-19-infected patients; resource allocation should be focused on } \\
\text { visits related to monitoring patients on ICB therapy for toxicities; it currently is unknown how patients } \\
\text { with COVID-19 on ICB therapy will react to immune-related adverse events }\end{array}$ \\
\hline
\end{tabular}

Abbreviations: SLNB, sentinel lymph node biopsy; ICB, immune checkpoint blockade; COVID-19, coronavirus disease 2019. 
TABLE 4. European Society for Medical Oncology Guidelines for Advanced Melanoma ${ }^{11}$

\begin{tabular}{|c|c|c|}
\hline Priority & Recommendation & Additional considerations \\
\hline \multicolumn{2}{|c|}{ Adjuvant systemic therapies for stage III melanoma } & \multirow{4}{*}{$\begin{array}{l}\text { Adjuvant therapy may be delayed up to } \\
12 \text { mo; adjuvant BRAF/MEK inhibitor therapy } \\
\text { may be initiated early, then later switch to } \\
\text { another immunotherapy less amenable to } \\
\text { telehealth; discourage inclusion in trials to } \\
\text { reduce visits }\end{array}$} \\
\hline High & $\begin{array}{l}\text { Clinical trial continuation (patient benefits } \\
\text { must outweigh risks, adapt procedures } \\
\text { where possible) }\end{array}$ & \\
\hline High/medium & $\begin{array}{l}\text { Patients with high-risk stage III disease: sentinel } \\
\text { lymph node deposit of } 1 \mathrm{~mm} \text { or greater than stage } \\
\text { Illa of the AJCC 8th ed }\end{array}$ & \\
\hline Low & $\begin{array}{l}\text { Sentinel lymph node deposit of } 1 \mathrm{~mm} \text { or less than } \\
\text { stage IIla AJCC 8th ed }\end{array}$ & \\
\hline \multicolumn{2}{|c|}{ Systemic therapies for nonoperable stage III/IV melanoma } & $\begin{array}{l}\text { Due to the risk of adverse events associated } \\
\text { with steroid use, discuss ipilimumab and }\end{array}$ \\
\hline High & Clinical trial continuation & $\begin{array}{l}\text { nivolumab vs single-agent PD-1 on a case- } \\
\text { by-case basis; patients with signs of } \\
\text { pneumonitis on computed tomography } \\
\text { should be tested for COVID-19 prior to } \\
\text { steroid treatment }\end{array}$ \\
\hline \multicolumn{2}{|c|}{ Radiotherapy for nonoperable stage III/IV melanoma } & rid steroids when possible \\
\hline High & $\begin{array}{l}\text { Stereotactic radiosurgery for brain metastases, } \\
\text { threatening lesions, or acute spinal cord compress }\end{array}$ & \\
\hline High/medium & Irradiation of symptomatic metastases & \\
\hline Low & $\begin{array}{l}\text { Irradiation of asymptomatic or nonthreatening } \\
\text { metastases; adjuvant radiotherapy postradical } \\
\text { lymphadenectomy to improve local control }\end{array}$ & \\
\hline
\end{tabular}

Abbreviations: AJCC, American Joint Committee on Cancer; COVID-19, coronavirus disease 2019.

Patients should wear a mask, remain 6-feet apart in the waiting room, and avoid touching objects until they enter the procedure room. Objects that the patient must touch, such as pens, should be cleaned immediately after such contact with either alcohol or soap and water for 20 seconds.

Office capacity should be reduced by allowing no more than 1 person to accompany the patient and ensuring the presence of only the minimum staff needed for the procedure. Staff who are deemed necessary should wear a mask continuously and gloves during patient contact.

Once in the procedure room, providers might be at elevated risk of contracting COVID-19 or transmitting SARS-CoV-2. A properly fitted N95 respirator and a face shield are recommended, especially for facial cases. N95 respirators can be reused by following the latest Centers for Disease Control and Prevention recommendations for reuse and decontamination techniques, ${ }^{13}$ which may include protecting the N95 respirator with a surgical mask and storing it in a paper bag when not in use. Consider testing asymptomatic patients in facial cases when they cannot wear a mask.

Steps should be taken to reduce in-person visits. Dissolving sutures can help avoid return visits. Follow-up visits and postprocedural questions should be managed by telehealth. However, patients with a high-risk underlying conditions (eg, posttransplantation, immunosuppressed) should continue to obtain regular skin checks because they are at higher risk for more aggressive malignancies, such as Merkel cell carcinoma.

\section{Conclusion}

The future trajectory of the COVID-19 pandemic is uncertain. Dermatologists should continue providing care for patients with skin cancer while mitigating the risk for COVID-19 infection and transmission of SARS-CoV-2. Guidelines provided by the NCCN and ESMO should help providers triage patients. Decisions should be made case by case, keeping in mind the availability of resources and practicing in compliance with local guidance. 
TABLE 5. Keratinocyte Carcinoma and Merkel Cell Carcinoma Guidelines ${ }^{8}$

\begin{tabular}{|c|c|}
\hline Intervention & Recommendation \\
\hline KC excision & $\begin{array}{l}\text { Excision of KC, including basal cell carcinoma, squamous cell carcinoma, and other rare cutaneous tumors, } \\
\text { should be postponed during the COVID-19 pandemic; as case rates continue to decline, excisions may } \\
\text { resume in accordance with local guidance, and consider the risk for contracting COVID-19 on a case-by- } \\
\text { case basis; excision may be considered if it there is a significant risk of metastasis or the physician estimates } \\
\text { that there is potential for debilitating progression within } 3 \text { mo }\end{array}$ \\
\hline Adjuvant therapy & $\begin{array}{l}\text { Adjuvant therapy should not be undertaken at this time in most cases; exceptions may be made if the lesion } \\
\text { involves invasion of large caliber nerves or meets criteria for AJCC cancer staging 8th ed N2 disease (multiple } \\
\text { nodes involved, extranodal extension, a nodal disease focus over } 3 \mathrm{~cm} \text { ), or if the patient is involved in a } \\
\text { currently operational clinical trial; multidisciplinary discussions via telehealth should be undertaken for patients } \\
\text { with unresectable disease when considering definitive radiotherapy or immunotherapy for local control or } \\
\text { palliative care }\end{array}$ \\
\hline MCC excision & $\begin{array}{l}\text { Excision of MCC should not be postponed during the COVID-19 pandemic due to the risk for early } \\
\text { metastasis and debilitating disease progression; exceptions may be made if the malignant lesion is } \\
<1 \mathrm{~cm} \text { in patients at greater risk for postoperative COVID-19 infection, including the elderly and debilitated } \\
\text { patients; office-based visits for Mohs surgery or WLE with standard margins may be considered, but defer } \\
\text { SLNB if operative rooms are unavailable; to facilitate possible later SLNB, excisions should be allowed to } \\
\text { granulate or should be closed primarily via cerclage or linear closure without undermining }\end{array}$ \\
\hline $\begin{array}{l}\text { Stage III MCC } \\
\text { excision }\end{array}$ & $\begin{array}{l}\text { Multidisciplinary discussions via telehealth should be undertaken for decisions of primary tumor } \\
\text { resection with complete lymphadenopathy vs off-label immunotherapy; consider the patient's medical } \\
\text { comorbidities (risk of COVID-19 sequelae), degree of tumor burden, and scarcity of resources; to } \\
\text { minimize exposure to and transmission of COVID-19, physicians should consider hypofractionated } \\
\text { radiation therapy (1-3 regimens) or } 40 \text { Gy over } 10 \text { treatments of } 4 \text { Gy per fraction }\end{array}$ \\
\hline
\end{tabular}

Abbreviations: KC, keratinocyte carcinoma; COVID-19, coronavirus disease 2019; AJCC, American Joint Committee on Cancer; MCC, Merkel cell carcinoma; WLE, wide local excision; SLNB, sentinel lymph node biopsy.

\section{REFERENCES}

1. Moletta L, Pierobon ES, Capovilla G, et al. International guidelines and recommendations for surgery during COVID-19 pandemic: a systematic review. Int J Surg. 2020;79:180-188.

2. Ueda M, Martins R, Hendrie PC, et al. Managing cancer care during the COVID-19 pandemic: agility and collaboration toward common goal. J Natl Compr Canc Netw. 2020:1-4.

3. Center for Medicare \& Medicaid Services. Non-emergent, elective medical services, and treatment recommendations. Published April 7, 2020. Accessed October 15, 2020. https://www.cms.gov/files/document/ cms-non-emergent-elective-medical-recommendations.pdf

4. Muddasani S, Housholder A, Fleischer AB. An assessment of United States dermatology practices during the COVID-19 outbreak. J Dermatolog Treat. 2020;31:436-438.

5. Coronavirus Resource Center, Johns Hopkins University \& Medicine. Rate of positive tests in the US and states over time. Updated December 11, 2020. Accessed December 11, 2020. https://coronavirus .jhu.edu/testing/individual-states

6. Middleton J, Lopes $\mathrm{H}$, Michelson $\mathrm{K}$, et al. Planning for a second wave pandemic of COVID-19 and planning for winter: a statement from the Association of Schools of Public Health in the European Region. Int J Public Health. 2020;65:1525-1527.

7. Liang W, Guan W, Chen R, et al. Cancer patients in SARS-CoV-2 infection: a nationwide analysis in China. Lancet Oncol. 2020;21:335-337.
8. National Comprehensive Cancer Network. Advisory statement for non-melanoma skin cancer care during the COVID-19 pandemic (version 4). Published May 22, 2020. Accessed December 11, 2020. https://www.nccn.org/covid-19 /pdf/NCCN-NMSC.pdf

9. National Comprehensive Cancer Network. Short-term recommendations for cutaneous melanoma management during COVID-19 pandemic (version 3). Published May 6, 2020. Accessed December 11, 2020. www.nccn.org/covid-19/pdf/Melanoma.pdf

10. Conforti C, Giuffrida R, Di Meo N, et al. Management of advanced melanoma in the COVID-19 era. Dermatol Ther. 2020;33:e13444.

11. ESMO [European Society for Medical Oncology]. Cancer patient management during the COVID-19 pandemic. Accessed Decemeber 11, 2020. https://www.esmo.org/guidelines/cancer-patient-management -during-the-covid-19-pandemic?hit=ehp

12. Guhan S, Boland G, Tanabe $\mathrm{K}$, et al. Surgical delay and mortality for primary cutaneous melanoma [published online July 22, 2020]. J Am Acad Dermatol. doi:10.1016/j.jaad.2020.07.078

13. Centers for Disease Control and Prevention. Implementing filtering facepiece respirator (FFR) reuse, including reuse after decontamination, when there are known shortages of N95 respirators. Updated October 19, 2020. Accessed December 11, 2020. https://www .cdc.gov/coronavirus/2019-ncov/hcp/ppe-strategy/decontamination -reuse-respirators.html 